\title{
Hepatic artery aneurysm, hereditary haemorrhagic telangiectasia, and peptic ulceration
}

\author{
JOHN R. CONDON, NORMAN C. TANNER, AND D. M. COWPER \\ From St. James's Hospital, Balham, London, and Joyce Green Hospital, Dartford
}

Hereditary haemorrhagic telangiectasis associated with hepatic artery aneurysm has only once been recorded in the literature (Graham, Eiseman, and Pryor, 1964).

This case is reported because the concurrence of these conditions, together with gastric and duodenal ulcers, serves to illustrate difficulties in the management of a patient with a bleeding diathesis who has four possible causes of gastrointestinal haemorrhage.

\section{CASE REPORT}

A.H., a 64-year-old woman with hereditary haemorrhagic telangiectasia, had had intermittent nose and gastrointestinal bleeding for four years; she gave a six-year history of periodic dyspepsia relieved by food and alkalis, and complained of an ill-defined pain in her back when she bent down to touch the floor.

Examination revealed no abnormal physical signs apart from telangiectases of the face, nose, lips, tongue, chest, and abdomen.

Barium meal showed a lesser curve gastric ulcer and scarring of the duodenal cap suggestive of a duodenal ulcer.

Endoscopy revealed multiple oesophageal and gastric telangiectases and a lesser curve gastric ulcer.

LAPAROTOMY A large pulsatile aneurysm involved the whole hepatic artery and extended to the porta hepatis (Fig. 1). The presence of gastric and duodenal ulcers was verified and a Polya-Hofmeister partial gastrectomy performed; mucosal telangiectases were found when the resected stomach was examined (Fig. 2).

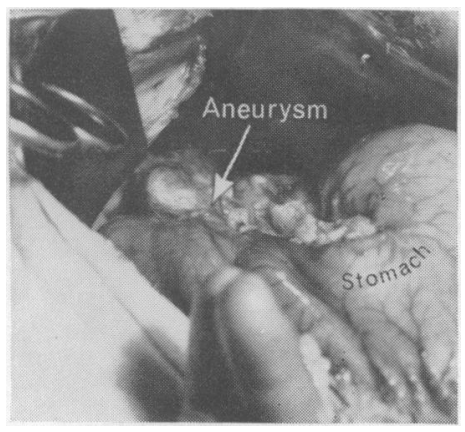

FIG. 1. The hepatic artery aneurysm and stomach.

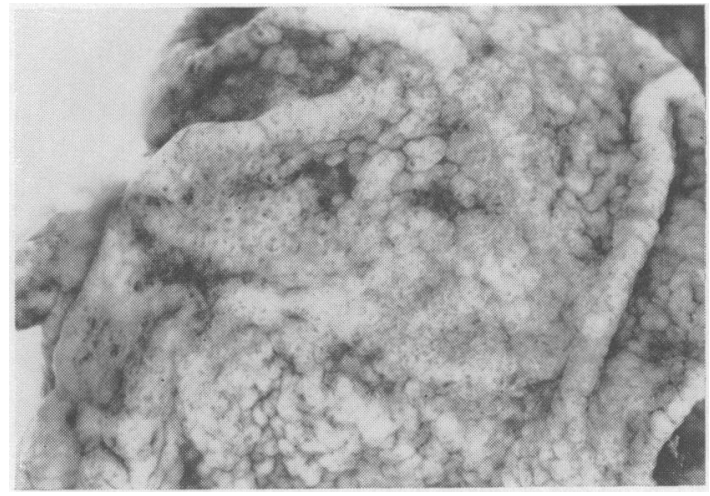

FIG. 2. Multiple telangiectases of stomach mucosa.

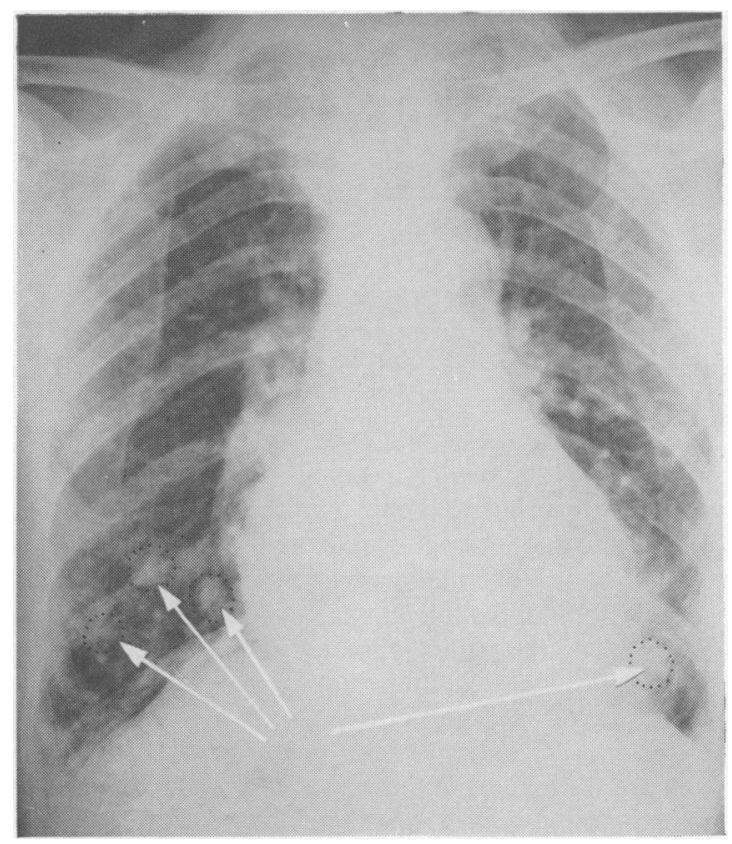

FIG. 3. Lung telangiectases. 


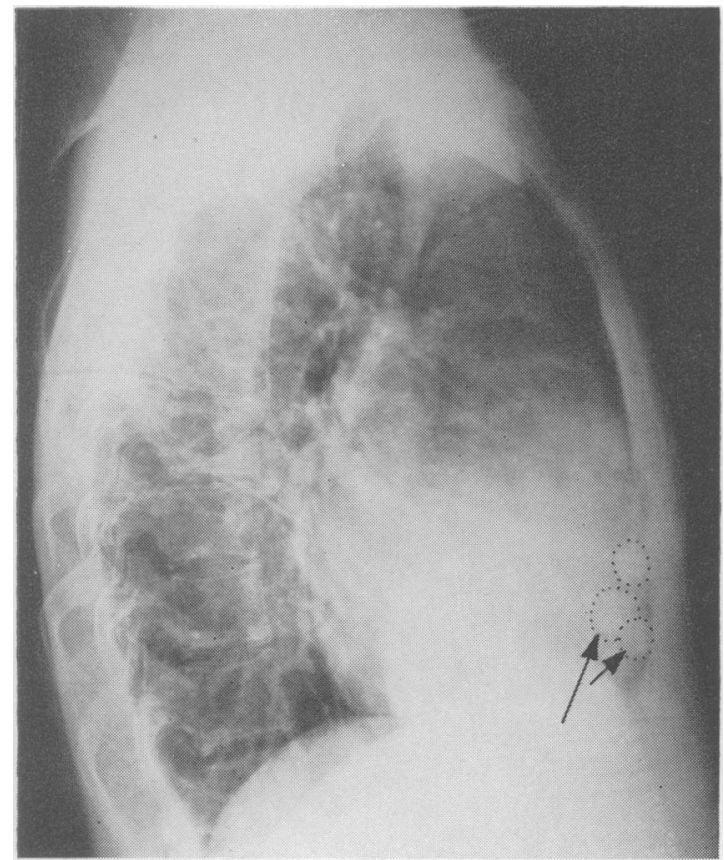

FIG. 4. Lung telangiectases.

Despite several severe haemorrhages from telangiectases at various sites the patient's survival to date is 12 years; during this time there has been no clinical evidence of dyspepsia or progression of the aneurysmal lesion, but her fingers have become clubbed and lung telangiectases have become manifest (Figs. 3 and 4).

\section{DISCUSSION}

Hepatic artery aneurysm may be either intra- or extrahepatic in position.

DIAGNOSIS OF EXTRAHEPATIC HEPATIC ARTERY ANEURYSM The preoperative diagnosis of hepatic artery aneurysm is difficult even when its three cardinal features-abdominal pain, jaundice, and gastrointestinal haemorrhage-occur together. Although the diagnosis is sometimes suggested by a palpable, pulsating abdominal mass or thrill and bruit detected over the abdominal wall, it is most commonly made at laparotomy for pain, jaundice, or haemorrhage, although it may be an incidental finding at operation performed for an unrelated condition.

The aneurysm sometimes ruptures into the bile ducts, gall bladder, or gut, eventually resulting in gastrointestinal haemorrhage. More commonly haemorrhage occurs into the peritoneal cavity giving rise to abdominal pain of dramatically sudden onset and severe signs of shock due to blood loss.
Abdominal pain, jaundice, and gastrointestinal bleeding may occur with ulcerating carcinoma of the head of the pancreas or ampulla of Vater, but in these conditions there is more likely to be a history of weight loss and change of bowel habit. Oesophageal and gastric varices may follow rupture of a hepatic artery aneurysm into the portal vein so that liver disease with portal hypertension may be mimicked. In this condition liver function tests are normal unless there has been prolonged obstructive jaundice due to pressure of the aneurysm on the bile ducts.

Hepatic artery aneurysm has been diagnosed radiologically by noting a calcified density to the right of the first lumbar vertebra (Jarvis and Hodes, 1954). Aortography not only confirms the diagnosis but if selective, e.g., by injecting dye into the hepatic artery, an absence or reduction of blood flow to the liver via this route may be demonstrated, indicating that the artery could be ligatured or excised without unduly altering the liver's blood supply (Howieson, 1963).

TREATMENT Persistent or repeated bleeding from an intrahepatic artery aneurysm is treated by partial hepatectomy or hepatic artery ligation (Cohen, Chow, and Seah, 1966).

Surgical treatment for extrahepatic artery aneurysm is usually considered necessary not only because spontaneous cure is rare but also because a high percentage of previously reported cases have died from haemorrhage.

If the aneurysm is leaking it may be treated by reconstructive aneurysmorrhaphy with closure in layers so as to maintain patency of the arterial lumen (Gordon-Taylor, 1943). Alternatively, the lesion may be resected and a patent arterial pathway to the liver reconstructed by means of an end-to-end anastomosis, splenic-hepatic artery anastomosis, or by the use of a graft.

In view of the technical difficulties involved with alternative procedures, hepatic artery ligation at the porta hepatis was considered in our patient, especially as this procedure resulted in only minimal signs of postoperative liver damage and no late sequelae, when it was performed under antibiotic cover in four non-cirrhotic patients (Andreassen, Lindenberg, and Winkler, 1962). The occurrence of liver failure following hepatic artery occlusion is probably dependent on the degree of collateral blood flow via the inferior phrenic, subcapsular, and, if present, accessory hepatic arteries, and as this was not known to be adequate in our case, the aneurysm was left untreated.

With the patient's liability to recurrent gastrointestinal haemorrhage correct management of 
future bleeding depended to a large extent on rapid identification of the site and cause of haemorrhage. Gastrectomy was performed not only for the relief of peptic ulcer symptoms but also in order to remove two potential sources of haemorrhage.

\section{SUMMARY}

A woman with hepatic artery aneurysm, hereditary haemorrhagic telangiectasia, gastric and duodenal ulcers is reported. Partial gastrectomy was performed to remove two potential sources of bleeding in order to simplify the management of any future gastrointestinal haemorrhage. She has survived 12 years since her operation.
It is a pleasure to thank Dr. J. C. Hogarth, of West Hill Hospital, Dartford, for allowing us to publish this case.

\section{REFERENCES}

Andreassen, M., Lindenberg, J., and Winkler, K. (1962). Peripheral ligation of the hepatic artery during surgery in non-cirrhotic patients. Gut, 3, 167-171.

Cohen, Y., Chow, K. W., and Seah, C. S. (1966). Intrahepatic aneurysm preoperatively diagnosed and treated by resection. Brit. J. Surg., 53, 602-606.

Gordon-Taylor, G. (1943). A rare cause of severe gastrointestinal haemorrhage. Brit. med. J., 1, 504-505.

Graham, W. P., III, Eiseman, B., and Pryor, R. (1964). Hepatic artery aneurysm with portal vein fistula in a patient with familial hereditary telangiectasia. Ann. Surg., 159, 362-367.

Howieson, J. L. (1963). Hepatic artery aneurysm. Radiology, 81, $598-600$.

Jarvis, L., and Hodes, P. J. (1954). Aneurysm of the hepatic artery demonstrated roentgenographically. Amer. J. Roentgenol., 72, 1037-1040. 